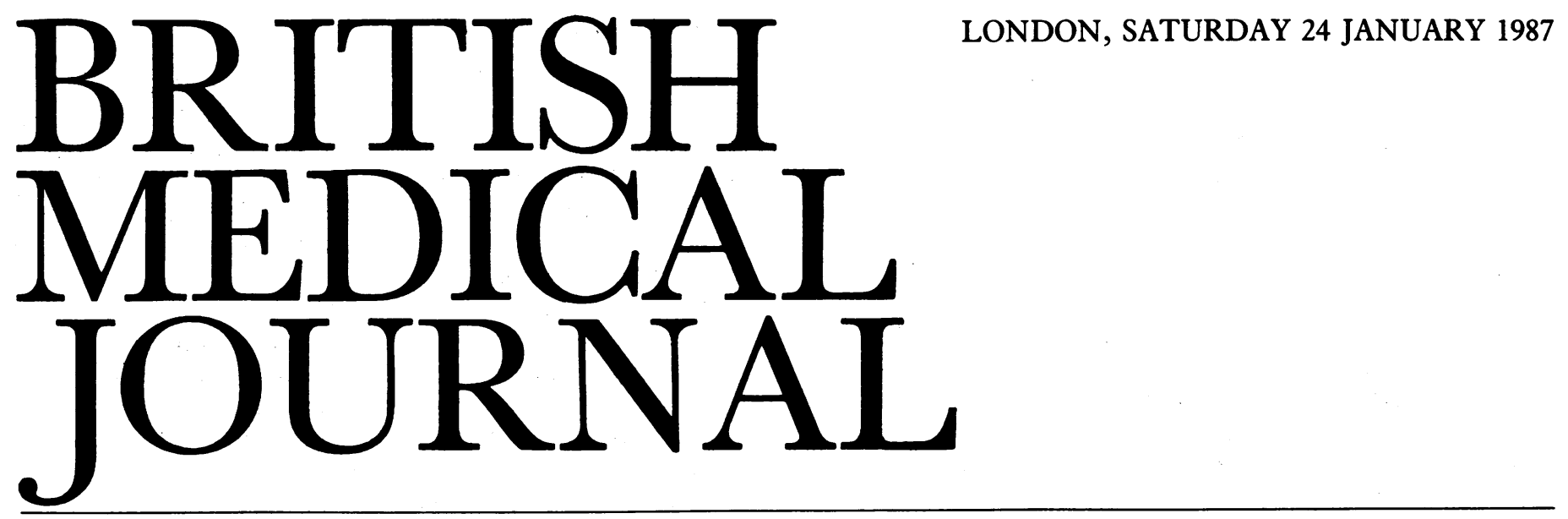

\title{
Time for action on hepatitis $B$ immunisation
}

The incidence of hepatitis B virus infection is increasing. In England and Wales reported cases reached almost 2000 in 1984 and resulted in 30 deaths. ${ }^{1}$ Chronic persistent and chronic active hepatitis, cirrhosis, and hepatocellular carcinoma are legacies of this infection. In Britain about $2-4 \%$ of the normal population have serological evidence of exposure to hepatitis $B$ virus, and at least $0.1 \%$ remain carriers. Some of these carriers will transmit infection parenterally, sexually, or perinatally. ${ }^{2}$ Among health service staff an increase of infection with hepatitis B virus of $25 \%$ has been recorded for $1980-4$ over the figure for $1975-9^{1}$; the annual incidence of infection with hepatitis $B$ virus among laboratory scientific staff, surgeons, physicians, and nurses is now 37, 25, 11, and 4 per 100000 respectively. This shows an important lifetime cumulative risk. ${ }^{1}$ The biggest increase in infection with hepatitis B virus has, however, been among intravenous drug abusers and homosexual men, ${ }^{1}$ though preliminary unpublished data reported to the Public Health Laboratory Service Communicable Disease Surveillance Centre show that the rate of infection has fallen substantially in this group in the past year.

In 1982 the Department of Health and Social Services issued guidance on who should receive hepatitis $B$ vaccine. ${ }^{3}$ Those identified included: staff working in residential institutions for the mentally handicapped; those in regular contact with identified carriers of hepatitis B virus - such as those working in haemophilia centres; laboratory workers regularly exposed to infected material; and staff seconded overseas to endemic areas. Patients identified for immunisation included those entering residential institutions for the mentally handicapped; those maintained on long term dialysis who plan to receive haemodialysis abroad; and non-immune sexual partners of e antibody negative carriers. In the four years since these recommendations were made notified cases have doubled. ${ }^{1}$ Vaccine uptake has been low even among health staff at risk, although the British Dental Association has recommended that all dentists, dental nurses, and hygienists in direct contact with patients should be immunised, and the Royal College of Nursing has advised nurses to do likewise. Efforts to immunise health care staff at risk have met with only a $56 \%$ uptake in one centre. ${ }^{4}$ Reasons for refusing immunisation included anxiety about adverse reactions, safety in pregnancy, and the possible transmission of the acquired immune deficiency syndrome (AIDS). But more than 2 million doses have been given worldwide, confirming the vaccine to be generally well tolerated. And there is no risk of transmitting the human immunodeficiency virus (HIV). ${ }^{5-7}$

(C) BRITISH MEDICAL JOURNAL 1987. All reproduction rights reserved.
One obstacle to widespread immunisation is the cost of the vaccine- $£ 63.50$ for a course of three injections-but too little attention has been paid to the substantial costs to the health service in coping with and preventing the long term complications of infection with hepatitis $B$ virus. For example, chronic active hepatitis is a progressive disease requiring frequent medical review and has a five year mortality of $25 \%$ to $50 \%^{89}$; serological screening for hepatitis B surface antigen is carried out, often repeatedly, on high risk groups, pregnant women, and donors of blood, organs, and semen; the infected patient in hospital presents a large nursing burden because of the need for isolation; and needlestick injuries occur with worrying regularity and demand individual assessment for treatment with hepatitis B immune globulin, which is expensive and in short supply. ${ }^{10}$ Furthermore, the health staff who develop infection with hepatitis B virus often lack a history of exposure thus reducing the efficacy of a control policy based on prophylaxis after exposure. Finally, occupationally acquired infection with hepatitis B virus renders health authorities liable for compensation under the Industrial Injuries Act.

Who then should be immunised and how should this be done? The hospital staff identified by the DHSS should actively be offered protection. ${ }^{3}$ Most important are: laboratory staff regularly handling infected samples; pathologists and technical staff doing necropsies; dental surgeons, nurses, and hygienists; staff in haemophilia units and genitourinary medicine clinics; endoscopy staff; accident and emergency staff; theatre staff in units where the risk of infection is high; and staff in liver and renal units, although those in renal units must be among the least at risk because of regular screening arrangements. This list is by no means exhaustive. ${ }^{11}$ Each health authority should actively review, cost, and implement a policy for immunising its employees. This can best be conducted by an occupational health department in liaison with employees' general practitioners.

In the community immunisation should be offered to those identified by the DHSS and also to infants of infected mothers, ${ }^{11}$ and a major initiative is necessary to contain infection with hepatitis B virus among sexually active homosexual men and intravenous drug abusers. Some 3-5\% of selected homosexual men are carriers of hepatitis B, while the lifetime risk of acquiring infection with hepatitis $B$ virus is greater than $50 \% .^{12}{ }^{13}$ The infectivity of hepatitis $B$ virus also appears to be increased among homosexual men simultaneously infected with human immunodeficiency virus. ${ }^{14}$ Immunisation would have the added bonus of preventing $\delta$ virus infection with its enhanced risks of progressive liver 
disease and fulminant hepatitis in those infected with hepatitis B virus. ${ }^{\text {is }}$

Immunisation of these two populations poses important problems. Homosexual men could most readily be immunised through departments of genitourinary medicine, and vaccine uptake is likely to be high. The need for serological screening, immunisation, and follow up for subsequent doses will, however, inevitably require additional resources, which should include health education. The cost effectiveness of such a policy has been well argued..$^{16}$ The men may also need to be revaccinated since antibodies may disappear in $15 \%$ and wane to non-protective titres in $27 \%$ after five years. ${ }^{17}$ The task of protecting the illicit drug abuser presents an even greater challenge. Immunisation through departments of genitourinary medicine or addiction centres is a possibility, although great emphasis on community follow up will be necessary for the policy to be successful. Failure to act promptly can lead only to an increase in the medical and economic burden of this preventable but incurable disease.

ROGER G FINCH

Consultant and Senior Lecturer in Microbial Diseases,

City Hospital and

University of Nottingham,

Nottingham NG5 1PB

1 Polakoff S. Acute viral hepatitis B: laboratory reports 1980-4. Br Med f 1986;293:37-8.

2 Woolf IL, Willias R. Significance of persistent HBs antigenaemia. Br Med f 1976;ii:807-8.

3 Yellowlees H, Poole AAB. Hepatitis B oaccine: guidance on use. London: DHSS, 1982. (CMO (82) 13.)

4 Triger DR. Hepatitis B immunization: experience in a provincial centre. Health Trends 1984;16:41-3.

5 Stevens CE, Taylor PE, Rubinstein P, et al. Safety of hepatitis B vaccine. $N$ Engl $\mathcal{J}$ Med 1985;312:375-6.

6 Papaevangelou G, Kallinikos G, Roumelioutou A, Politou K. Risk of AIDS in recipients of hepatitis b vaccine. N Engl I Med 1985;312:376-7.

7 Kessler $H$, Chase $R$, Harris R, Jensen D, Levin S. HTLV-III antibodies after hepatitis vaccination. Lancet 1985;i:1506-7.

8 Smiccination. Lancet 1 (n) 279 patients with chronic hepatitis B liver disease. [Abstract.] Hepatology 1981;1:548.

9 disease. [Abstract.] Hepatology $1981 ; 1: 548$. In: Cohen S, Soloway RS, eds. Chronic active liver disease. London: Churchill Livingstone, In: Cohen $S$,
$1983: 73-80$.

10 Flewett TH. Can we eradicate hepatitis B? BrMed I 1986;293:404-5.

11 Zuckerman AJ. Priorities for immunisation against hepatitis B. Br Med $\mathcal{Y}$ 1982;284:686-8.

12 Coleman JC, Waugh M, Dayton R. Hepatitis B antigen and antibody in a male homosexua population. Brf Vener Dis 1977;53:132-4.

13 Tedder RS, Cameron CH, Wilson-Crooe R, et al. Contrasting patterns and frequency of antibodies to the surface, core and $e$ antigens of hepatitis $B$ virus in blood donors and in homosexual patients. F Med Virol 1980;6:323-32.

14 Perrillo RP, Regenstein FG, Roodman ST. Chronic hepatitis B in asymptomatic homosexual men with antibody to the human immunodeficiency virus. Ann Intern Med 1986;105:382-3.

15 Smedile A, Verme G, Cargnel A, Dentico P, Opolon P, Vergani D. Influence of delta infection on severity of hepatitis B. Lancet 1982;ii:945-7.

16 Adler MW , Belsey EM, McCuthan JA, Mindel A. Should homosexuals be vaccinated against hepatitis B? Cost and benefit assessment. BrMed I 1983;286:1621-4.

17 Hadler SC, Francis DP, Maynard JE, et al. Long-term immunogenicity and efficacy of hepatitis B vaccine in homosexual men. N Engl I Med 1986;315:209-14.

\section{The locked in syndrome}

The first description of the locked in syndrome may not have been by a doctor but by a writer-Emile Zola in Thérèse Raquin in $1868 .{ }^{12}$ Camille is murdered by Thérèse and her passionate, adulterous lover, Laurent. Saddened by her son's death the pitiful mother, Madame Raquin, has a stroke: "Her tongue turned to stone. Her hands and feet stiffened. She was struck dumb and motionless." After a partial respite "she had only the language of her eyes, and her niece had to guess what she wanted." Later "she could communicate quite easily with that imprisoned mind buried alive in a dead body. . . . She had learnt to use her eyes like a hand or a mouth, to ask and give thanks, and in a strange way made up for the organs she had lost." She later discovered the lovers' treachery in murdering her son and then "made frantic efforts to ... put all her hatred into her eyes." The wicked couple are eventually driven to take their own lives bye poison. "Madame Raquin, stiff and silent, contemplate them at her feet, unable to feast her eyes enough, eyes thas: crushed them with brooding hate."

It was more than a century later that Plum and Posnem introduced the term the "locked in syndrome."3 Patient with the syndrome are tetraplegic and mute but have pre:served sentient consciousness. They are thus immobile and locked in but can communicate by blinking and vertical eye movements. ${ }^{45}$ They are aptly described as "de-efferented.'을 The condition is different from coma, the "persistent vegetative state," and akinetic mutism.

Coma, "a state of unrousable unresponsiveness," is thळ best known of the states of altered consciousness. It $\vec{S}$ principal cause is a disturbance of the alerting wakefulness mechanisms that operate through the ascending reticulafs formation in the brain stem and diencephalon. ${ }^{3}$ This happens? when a sizable lesion in a hemisphere (a mass, haematoma infarct, or oedema) encroaches on, distorts, or compresseso the rostral brain stem. Infratentorial lesions may cause comás by direct pressure on the brain stem; metabolic or anoxiof insults can produce the same end result.

After severe brain damage consciousness may return, usually in two to four weeks, but the victim may be left in 9 persistent vegetative state. ${ }^{6}$ This describes a state in which the patient survives for months or years and is awake and moves a little but shows no sign of conscious intelligence Most die of the complications of immobility rather than front the widespread damage to the neocortex.

"Akinetic mutism" (or coma vigil) was first described byo Cairns and others in 1941 in a patient with a epidermoid cyst of the third ventricle. ${ }^{7}$ These patients lie motionlesso mindless, and unaware of their surroundings but show sleep wake cycles. They may be capable of reflex movement withdrawing from a painful stimulus, and may make semiळ purposeful movements but usually cannot be stimulated to do so. The condition may be caused by tumours of the thirc ventricle or by large lesions-most commonly traumatic anoxic, or vascular ${ }^{8}$ - affecting both hemispheres and whiclộ. have destroyed the frontal cortex,${ }^{9}$ basal ganglia, thalamus, ${ }^{10}$ or diencephalon." With such massive damage very few patients survive.

The locked in syndrome usually results from infarction haemorrhage, or demyelination in the ventral pons oß medulla: the lesion paralyses the pyramidal tracts to the limbs and the lower cranial nerves but spares the tegmentum? thereby preserving the supranuclear pathway to the oculaf motor mechanism. ${ }^{12}$ Consciousness depends on the sparing of the upper pontine tegmentum above the level of the trigeminal nucleus. ${ }^{35}$

Associated brain stem signs are pointers to more precise localisation, which admittedly has little therapeutic imo portance. Electroencephalograms are usually normalo consistent with the wakeful state. ${ }^{512}$ Brain stem evoke $\phi$ potentials show loss or impaired amplitude of waves IV and $\mathrm{V}$, indicating damage to the tegmentum. ${ }^{13}$ Lateral gaze is often lost, but vestibulo-ocular reflexes tested by ice wate irrigation may be retained. Destruction of the descending supranuclear path for voluntary gaze is the likely mechanism for this dissociation between voluntary and reflex movement The occurrence of peculiar rhythmic but involuntary downo ward movements of the eyes called "ocular bobbing localises the lesion to the pons. ${ }^{514}$ 